\title{
Notch is required for successive cell decisions in the developing Drosophila retina
}

\author{
Ross L. Cagan ${ }^{1}$ and Donald F. Ready ${ }^{2}$ \\ ${ }^{1}$ Department of Biology, Princeton University, Princeton, New Jersey 08544-1003 USA; ${ }^{2}$ Department of Biological Sciences, \\ Purdue University, West Lafayette, Indiana 47907 USA
}

\begin{abstract}
Mutations in the Notch locus affect a variety of developmental decisions in Drosophila. In this paper, we examine the role of Notch in the developing retina. We reduced Notch activity at successive intervals during development of the retina, and then examined the effect on individual cells. When Notch activity was reduced, cells responded by selecting inappropriate developmental pathways. We found that all cell types appear to require Notch when establishing their fate. To examine further Notch's role in eye development, we examined two alleles of Notch-split and facet-glossy. split flies show defects in the initial clustering of photoreceptors, whereas the defects in facet-glossy flies are due to the misrouting of presumptive primary pigment cells into the secondary pigment cell pathway. Our results suggest that Notch plays a permissive role in the cell-cell interactions used to assemble the eye.
\end{abstract}

[Key Words: Drosophila; Notch; split; facet-glossy; retina]

Received May 10, 1989; revised version accepted June 16, 1989.

Communication between cells in contact is a critical aspect of development; it allows cells to coordinate their physiology, including patterns of gene expression. In Drosophila, the use of mutations has identified several elements in a communication pathway that regulates neural development (Campos-Ortega 1988). Beginning with Poulson's (1937) observation of neural hypertrophy in Notch embryos, a series of experiments has led to the idea that a contact-mediated signal normally inhibits the majority of potentially neural cells from actually becoming neurons (Lehmann et al. 1983; Doe and Goodman 1985). This inhibition fails in Notch mutants. Mutations in any of the allied 'neurogenic' genes likewise can cause hypertrophy of the embryonic nervous system. The spectrum of defects displayed by Notch mutants indicates a role for the gene beyond the embryo and outside the nervous system (Welshons 1965; Artavanis-Tsakonis 1988).

The deduced primary sequence of Notch also supports its role in local cell-cell interactions (Wharton et al. 1985; Kidd et al. 1986). The Notch product is a transmembrane protein that contains a large, cysteine-rich extracellular domain and shares several structural features with the product of lin-12, a gene in the worm Caenorhabditis elegans that is required for particular cell decisions (Greenwald 1985; Yochem et al. 1988). lin-12 is necessary for the specification of several cell fates, many of which require cell-cell interactions (Kimble 1981; Greenwald et al. 1983). The prediction that the Notch product is a large transmembrane protein with a structure similar to the product of $l i n-12$ raises the possibility that Notch is involved directly in cellcell interactions.

Several observations point to a role for Notch in eye development. The Notch alleles split and facet-glossy cause defective ommatidial development, resulting in an irregular, rough eye (Welshons 1965). Temperature-sensitive Notch mutants have been used to define the time of the gene's action in eye development. Notch-ts1 $\left(N^{t s 1}\right)$ reduces Notch activity at elevated, nonpermissive temperatures (Shellenbarger and Mohler 1975). In the late larva, a band of susceptibility to temperature shifts is seen that corresponds roughly to the advancing wave of retinal morphogenesis (Foster and Suzuki 1970; Shellenbarger and Mohler 1978). Temperature shifts in early pupal life mimic facet-glossy (Shellenbarger and Mohler 1975).

The eye is a self-organizing neural epithelium in which stereotyped cell contacts regulate development (Tomlinson and Ready 1987; R.L. Cagan and D.F. Ready, in prep.). Its simplicity permits a cell-by-cell analysis of defects in mutant eyes. The eye is composed of several hundred unit eyes, or ommatidia. Each ommatidium contains eight photoreceptors R1-R8, four cone cells, and two primary pigment cells. Surrounding the ommatidia is a hexagonal lattice of secondary pigment cells, tertiary pigment cells, and bristles (Fig. 1). We used a temperature-sensitive allele of Notch to examine its role in the cell decisions needed to construct a normal ommatidium. Flies were shifted to a nonpermissive temperature, and then returned to the permissive temperature; the resulting defects were examined. We also examined 


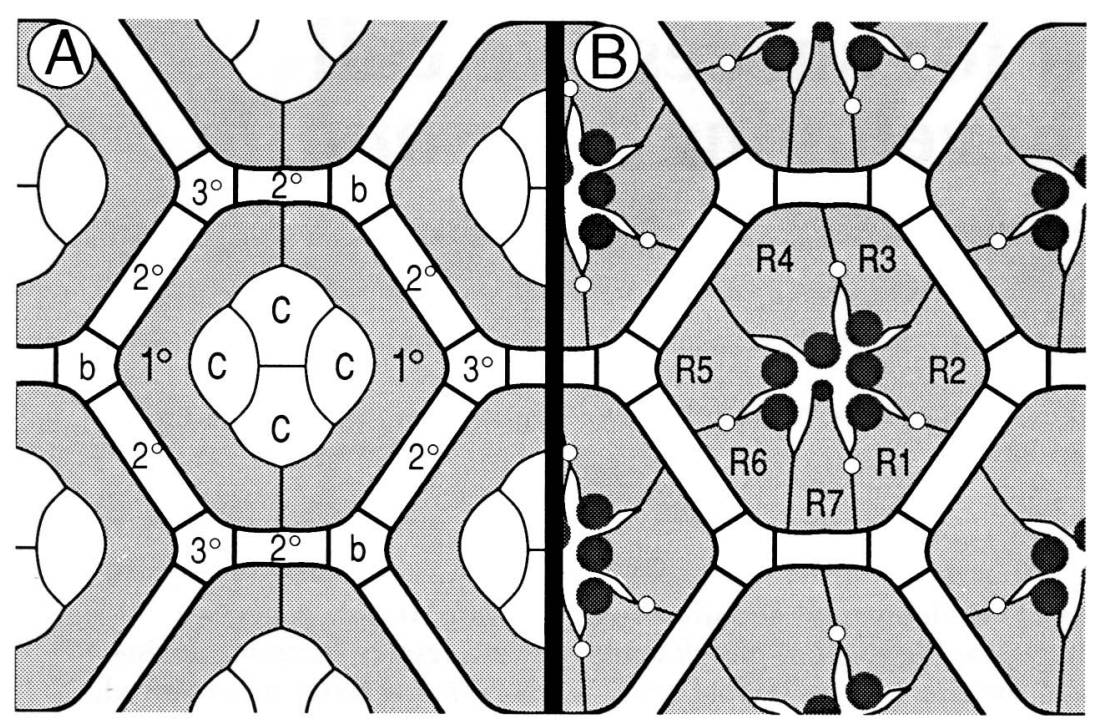

Figure 1. Two schematic cross sections of a mature ommatidium. $(A)$ Near the top. Four central cone cells $(\mathrm{c})$ are surrounded by two primary pigment cells $(1 \%$. Shared between ommatidia are six secondary pigments cells $\left(2^{\circ}\right)$, three tertiary pigments cells $\left(3^{\circ}\right)$, and three bristles (b). $(B)$ A deeper view of the same ommatidium. Seven of the eight photoreceptors $(R 1-R 7)$ are visible; photoreceptor R8 is deeper. Each projects a darkly staining rod, the rhabdomere, into the center of the ommatidium. The primary pigment cells lie only apically and are not visible; the cone cells are visible only as thin threads between the photoreceptors. The identity of cells in the surrounding hexagonal lattice is the same as in $A$. Anterior is to the right. the developing eyes of split and facet-glossy flies. We show that Notch is required by cells of all types in the retina, neural and nonneural, at the time they choose their fate. These results suggest that Notch plays a permissive rather than an instructive role in cell-cell communication in the eye.

\section{Results}

\section{Reducing Notch activity affected photoreceptor and} cone cell development

Ommatidia are built in a sequential and stereotyped fashion Figure 2A provides a view of early photoreceptor development in a mature wild-type larval disc. Photoreceptor differentiation begins in the third-instar larva. In the eye portion of the eye/antennal disc, or eye disc, a furrow forms at the posterior edge and moves anteriorly. This morphogenetic furrow marks the beginning of photoreceptor clustering. In the region ahead of the morphogenetic furrow, cells appear undifferentiated with no clustering evident. As the furrow progresses anteriorly, clusters of cells at the trailing edge pinch off and close together to form a group of six to seven cells. These cells are arranged as five to six cells grouped in a semicircle on the posterior face of a center cell - one of the mystery cells (Tomlinson and Ready 1987; D.F. Ready 1989). Within the five to six cells on the posterior rior face, one cell in the center soon stains more darkly; this is the future photoreceptor R8.

In more mature clusters, five cells pinch shut and form a five-cell precluster. The precluster contains the future R2, R3, R4, R5, and R8. Following a wave of mitoses, photoreceptors R 1 and $\mathrm{R} 6$ are added, then R7. The four cone cells then are added to the growing cluster; first the anterior and posterior cones join the cluster, then the equatorial and polar cones. The forward march of the furrow generates a gradient of development in the disc such that posterior clusters are more mature than clusters closer to the furrow. Therefore, temperature shifts of a single larval disc reduce Notch activity across a succession of developmental stages.

Early shifts produced extra photoreceptors and cone cells When third-instar $N^{t s 1}$ larvae were shifted to $32^{\circ} \mathrm{C}$ for 4-24 hr, nearly all cells just posterior to the morphogenetic furrow differentiated into neurons, as judged by their extension of axons and staining with cobalt sulfide and anti-HRP antibodies (Figs. 2B and 3). Widespread neuralization of cells at the furrow continued as long as the flies were kept at the nonpermissive temperature. This period continued throughout late larval development and at least $6 \mathrm{hr}$ after pupariation, the period during which ommatidial clusters arise from the morphogenetic furrow.

Four-hour temperature shifts affected enough photoreceptors to account for about two to three rows, while 24-hr shifts gave rise to a band of neural cells spanning approximately a quarter of the retina. This rate is consistent with the normal addition of a new row of clusters about every $2 \mathrm{hr}$ (Campos-Ortega 1980). Supernumerary neurons were grouped into enormous clusters along the furrow. When the flies were returned to $20^{\circ} \mathrm{C}$, newly made clusters again developed normally; neuralization of a column of cells appeared to have no effect on development of later clusters.

Normally, a wave of cell divisions occurs three to six rows posterior to the morphogenetic furrow. However, injections of bromodeoxyuridine in temperature-shifted larvae indicated that no cells divided in the region of neuralization. Therefore, supernumerary photoreceptors were recruited from the pool of uncommitted cells normally surrounding developing clusters, and not from newly produced cells.

Beginning about $60 \mathrm{hr}$ after pupariation, photoreceptors form specialized light-sensitive structures, the rhabdomeres. In 60-hr eyes of animals shifted as larvae, then returned to $20^{\circ} \mathrm{C}$, the supernumerary neurons formed rhabdomeres, expressing their photoreceptor identity. They were covered by many overlying cone 


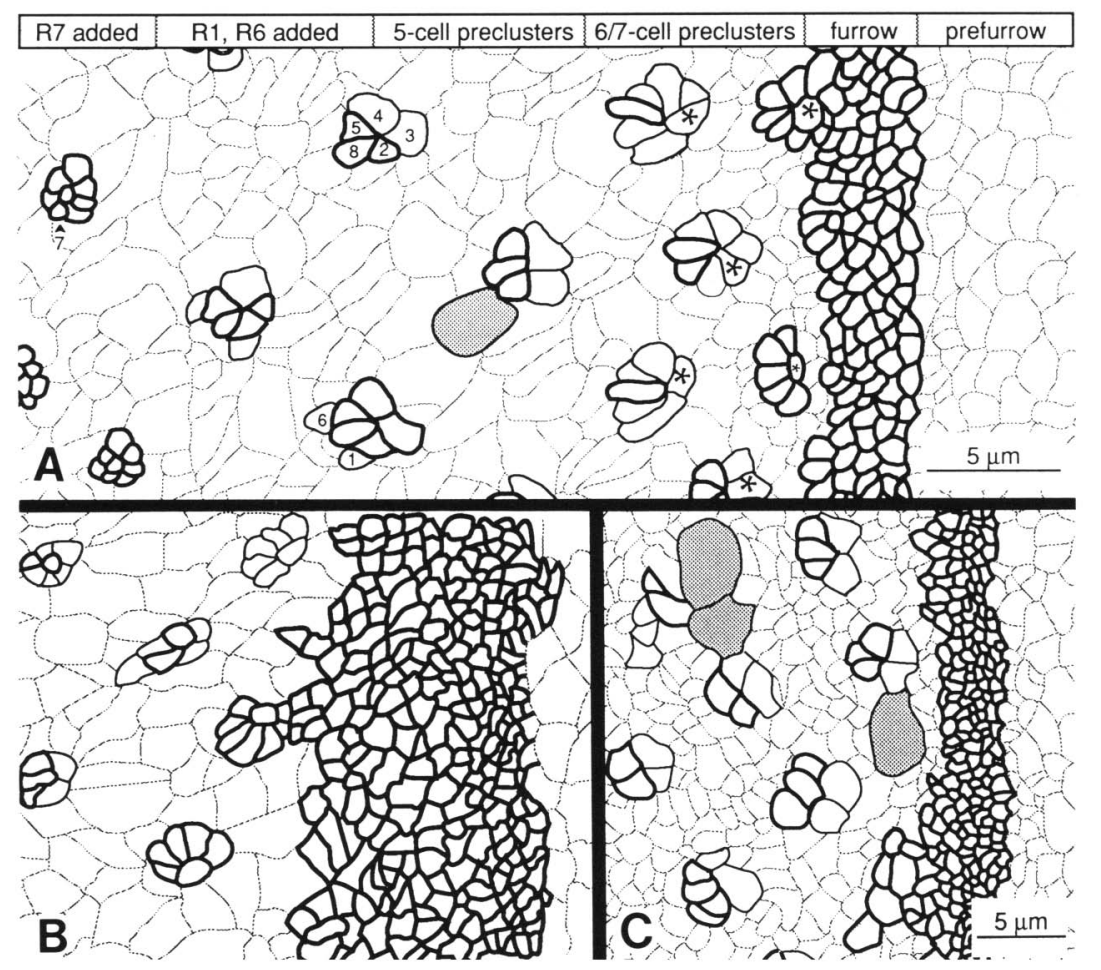

Figure 2. A detailed view at the morphogenetic furrow. Tracings of the surface of three third-instar discs stained with cobalt sulfide. Thicker lines represent darker staining; cells shaded with gray are dividing. $(A)$ Wild-type disc. Labels at the top indicate six early stages of ommatidial development. As differentiation moves anteriorly, undifferentiated cells (prefurrow) collect into the morphogenetic furrow (furrow). Groups of six to seven cells break from the furrow (6/7-cell preclusters); the central mystery cell is indicated with an asterisk. One darkly staining cell at the center of the cells extending from the central mystery cell will become photoreceptor R8. More posteriorly, five-cell preclusters are formed (5-cell preclusters). Dividing cells are found in this region. Rl and R6 are added, then R7. In later clusters the four cone cells are added (not shown). (B) A $N^{\text {ts1 }}$ eye disc temperature-shifted for $8 \mathrm{hr}$, then dissected immediately. It contains an extended region of darkly staining cells; most of these cells will differentiate as photoreceptors. More posteriorly, differentiating cells cluster together poorly. $(C)$ split disc. The furrow is normal in size. Cells often cluster abnormally immediately out of the furrow, much as in $B$. Cell divisions occur in normal regions and occasionally in abnormal regions: a cell division is occurring near the furrow. Bar in $C$ applies to $B$ and $C$; anterior is to the right. cells, although in some regions neuralization was too extensive for all photoreceptors to be covered, and several showed through apically. The enormous clusters were often at least partially surrounded by a few elongated pigment cells (Fig. 4B).

In the $N^{t s 1}$ adult, a scar was produced across the eye when larvae were temperature-shifted for at least $10 \mathrm{hr}$. Sections through scarred eyes revealed many of the same defects seen in the larva. Clusters with too many or too few photoreceptors were found (Fig. 5). In addition, individual photoreceptors were often defective, especially in the neuralized region. Photoreceptors were found to

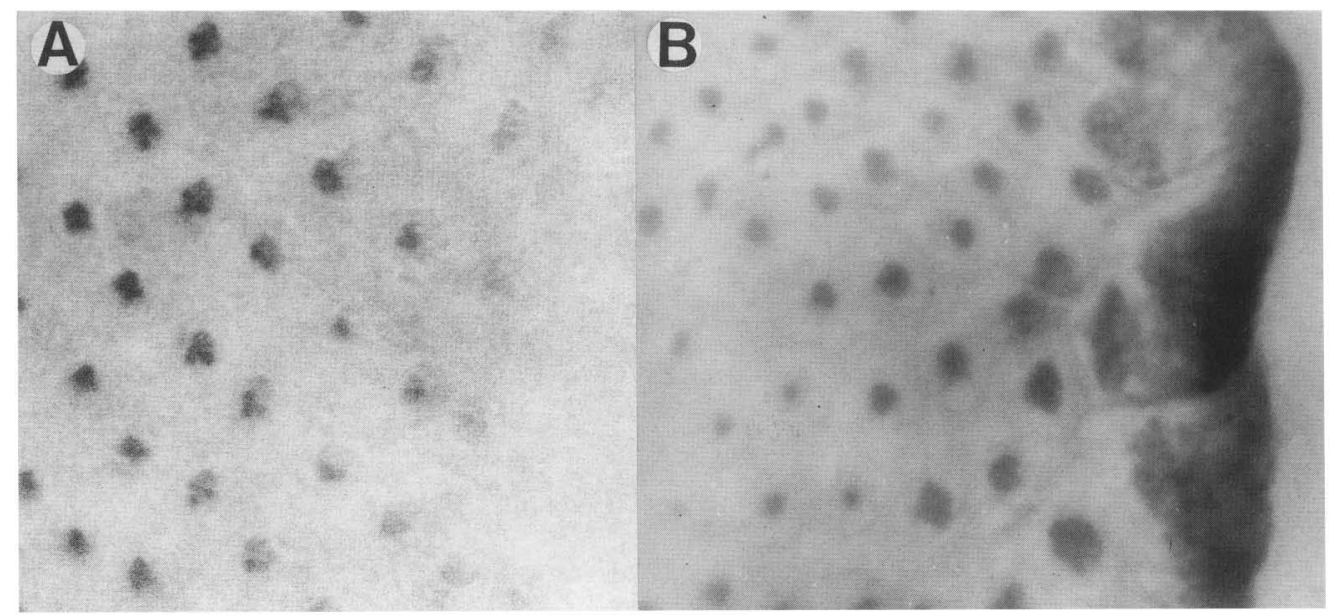

Figure 3. Anti-HRP antibody staining of wild-type and $N^{t s 1}$ third-instar eye discs. Morphogenetic furrow is at the right of each panel. (A) Wild-type disc. As cells group together into developing ommatidia, they label with anti-HRP antibody. Ommatidial clusters are spaced evenly. $(B) N^{t s 1}$ disc shifted to nonpermissive temperature for $14 \mathrm{hr}$. Just posterior to the furrow, anti-HRP staining highlights a bulging lawn of photoreceptors. More posteriorly, ommatidial clusters are still abnormally large and poorly spaced. Bar, $10 \mu \mathrm{m}$; anterior is to the right. 


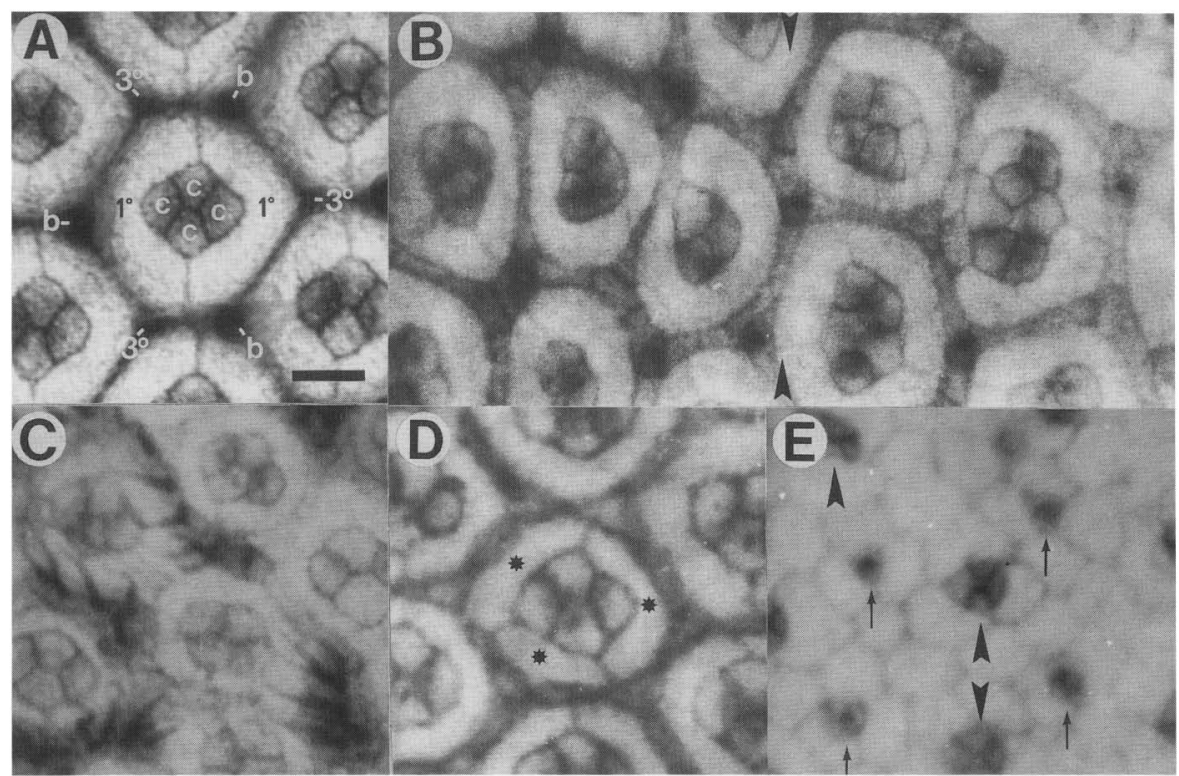

Figure 4. Temperature shifts affect a variety of cell decisions. The apical surface of five $N^{t s 1}$ discs that were shifted briefly to $32^{\circ} \mathrm{C}$ at successive stages. The discs were shifted for $8 \mathrm{hr}$, then returned to the permissive temperature and allowed to mature to $65 \mathrm{hr}(A-D)$ or $55 \mathrm{hr}(E)$. The discs were stained with cobalt sulfide to highlight the surface. $(A)$ One ommatidium from an unshifted pupa. The cones cells $(\mathrm{c})$ and primary pigment cells $\left(1^{\circ}\right)$ are surrounded by bristles $(\mathrm{b})$, and secondary and tertiary pigments cells $\left(3^{\circ}\right)$. The secondary pigment cells are stretched between the bristles and tertiary pigment cells (see Fig. 1A). The photoreceptors are not visible at the surface of this stage. (B) The 0 - to 8 -hr shift, dissected at $65 \mathrm{hr}$. To the right of the arrowheads, ommatidia contain too many cone cells; beneath is an excess of photoreceptors. To the left of the arrowheads, ommatidia contain too few cone cells. (C) The 8- to 16-hr shift, dissected at $65 \mathrm{hr}$. The lattice is dominated by bristles. (D) The 16- to 24-hr shift, dissected at $65 \mathrm{hr}$. Cone cells are surrounded by three primary pigment cells $\left(^{*}\right)$ instead of the normal two. Also, the surrounding hexagonal lattice is bald. $(E)$ The $28-$ to 36-hr shift, dissected at $55 \mathrm{hr}$. Large arrowheads indicate cone cells, which are smaller due to crowding from a preponderance of cells. No primary pigment cells are present. Small arrows indicate bristles. The 55 -hr eyes are shown because older eyes photograph poorly. This is a phenocopy of facet-glossy (Fig. 9). Bar, $3 \mu \mathrm{m}$ for $A$ and $D, 5 \mu \mathrm{m}$ for $B, C$, and $E$; anterior is to the right.

contain such aberrations as two distinct rhabdomeres protruding from a single photoreceptor or, rarely, no rhabdomere at all.

Normally, the secondary and tertiary pigment cells form vertical partitions and a floor (the fenestrated membrane) that shape and support the photoreceptors. Because most of the cells in the neuralized region were photoreceptors-made at the expense of cells that would later become secondary and tertiary pigment cells - they were left without vertical guides or a floor. Consequently, the cell bodies of the photoreceptors in the adult Drosophila generally were twisted and bent at various angles, and often were found beneath the deformed floor of the retina. The few remaining pigment cells were filled with what appeared to be necrotic vesicles (Fig. 5). As the adult aged, cell death occurred in the

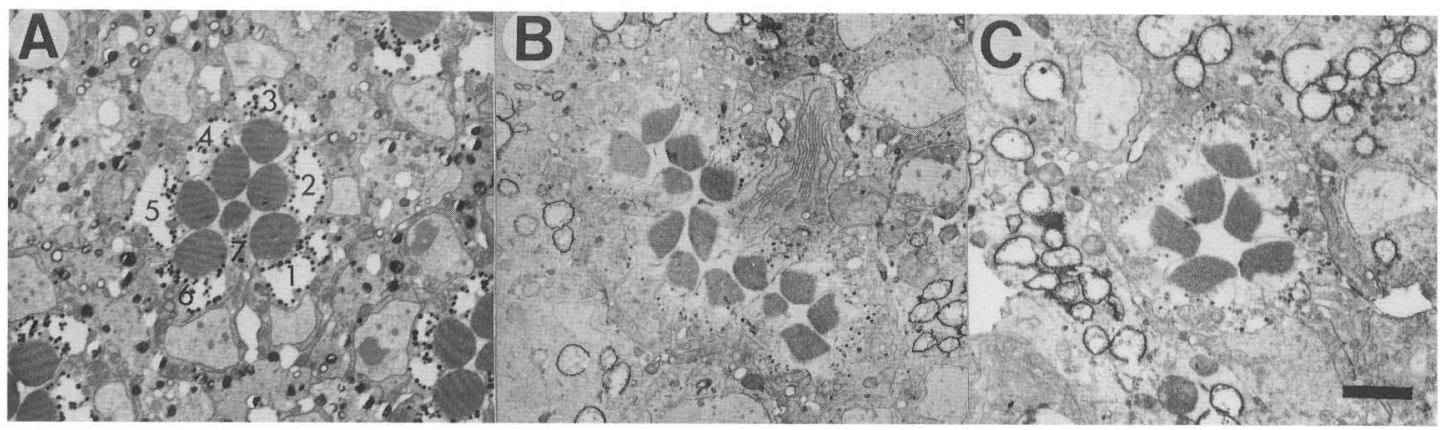

Figure 5. Early temperature shifts affect the number of photoreceptors. Transmission electon micrographs of wild-type and $N^{t s 1}$ adults. In each panel, a single ommatidium is shown. $(A)$ Wild type, $20 \mu \mathrm{m}$ below the surface. Compare with Fig. 1B. Rhabdomeres highlight the seven photoreceptors $(1-7)$ seen at this level. $(B)$ An anterior ommatidia about $50 \mu \mathrm{m}$ below the surface from $N^{t s t}$ fly shifted $0-8 \mathrm{hr}$ after pupation. Ommatidium is composed of at least 14 photoreceptors. The surrounding pigment cell lattice contains membrane-bound vesicles. $(C)$ A more posterior ommatidium from the same fly as in $B$. It contains only six photoreceptors at this level; a cell resembling R8 lies just below. The surrounding lattice is also filled with vesicles. Bar, $5 \mu \mathrm{m}$; anterior is to the right. 
scar, resulting in dark regions that were visible under a dissecting microscope.

Early shifts also blocked later addition of photoreceptors and cone cells Posterior to the neuralized region, the most mature clusters were unaffected. But between these normal clusters and the neuralized region, clusters often contained fewer than the normal complement of eight photoreceptors. In larval discs shifted for as short a time as $4 \mathrm{hr}$, then examined in 60-hr pupae or adults, these smaller ommatidia were often missing one to two cells. Most commonly, a single cell was lost; the positions of the remaining cells in the cluster suggest that the missing cells was often $\mathrm{R} 7$, normally the last photoreceptor recruited into the cluster. Consistent with this idea, loss of the cell occurred approximately seven rows behind the neuralized region, where $\mathrm{R} 7$ would normally be recruited (Tomlinson 1985; Tomlinson and Ready 1987). The loss of photoreceptors persisted in the adult (Fig. 5C). Smaller clusters also were found occasionally within the anterior and posterior edges of the neuralized region. These clusters were organized poorly and probably were due to general ommatidial derangement.

Still further posteriorly, in ommatidia that were more mature at the onset of the shift, cone cells were lost. Rather than the normal complement of four cone cells, one to three cone cells appeared over the clusters /Fig. 4B). This reduction in cone cells occurred for two to three rows, although the underlying eight photoreceptors generally appeared normal. The identity of a cone cell can be determined in the pupa by its position between photoreceptors. When a single cone cell was missing, the positions of the remaining three cells suggested that the missing cone cell was often the equatorial or polar cone cell, although sometimes cone cells were found in entirely novel positions between the photoreceptors.

\section{Reducing Notch activity affected the mechanosensory bristles}

Bristle groups are derived from divisions of single bristle mother cells Bristle formation begins soon after pupariation. Unlike the posterior-to-anterior development of the ommatidia, bristle development begins at the center and radiates outward toward the edge. An exception is the anterior and posterior edges of the disc, which are typically bald. Early in pupation, bristles arise between ommatidia when a single bristle mother cell divides to produce the four cells of the bristle group-the tormogen, trichogen, neuron, and glial cell. By midpupation, a typical ommatidium is surrounded by three bristle groups (Fig. 1). Cell divisions at the center of the disc, which produce the earliest bristles, normally being at about $20 \mathrm{hr}$, with $\mathrm{S}$ phase occurring $6 \mathrm{hr}$ before (R.L. Cagan and D.F. Ready, in prep.) Using bromodeoxyuridine, the time course of the appearance of the bristle mother cell in unshifted $N^{t s 1}$ flies was found to be the same as in wild-type Canton Special flies.
Larval shifts produce mispositioned bristles The placement of the bristle groups was affected in approximately the same regions that lost photoreceptors and cone cells. Normally, bristle groups are found at the anterior side of the horizonal secondary pigment cells (Fig. 1). About six rows behind the neuralized area, bristles often were misplaced to the posterior side of the secondary pigment cell. In some regions, this switch occurred in more than one-third of the ommatidia. This misplacement of the bristle groups occurs sporadically in normal eyes, but at a far lower frequency. Because bristles do not appear in the eye until the developing fly pupates, this result suggests that placement of the bristles can be affected by the earlier photoreceptor or cone cell differentiation. However, mispositioning of bristles was not correlated obviously with any visible defect in the ommatidial clusters.

Early pupal shifts produced extra bristles Temperature shifts between 6 and $16 \mathrm{hr}$ after pupariation produced an increase in the number of bristles between ommatidia. Although a 4-hr temperature shift produced some extra bristles, at least $8 \mathrm{hr}$ were required for a dramatic increase. For example, after an 8 - to $16-\mathrm{hr}$ shift, most of the cells surrounding the ommatidia formed bristles (Figs. 3C, 6, and 7). A single cluster often was surrounded by 15 or more bristles, instead of the normal 3 . The number of pigment cells was reduced severely, and ommatidia were aligned poorly. Bromodeoxyuridine injected during the course of the shift was incorporated into the nucleus of each cell in the bristle groups. This suggests that, as in normal bristle development, the extra groups arose from divisions of a common mother cell and not simply by the gathering of uncommitted cells. The earliest shifts increased the number of bristles 4-6 hr before cells could be labeled with bromodeoxyuridine, suggesting that a cell is determined to form a bristle group several hours before new DNA is synthesized in preparation for mitosis.

A 6- to $10-\mathrm{hr}$ shift produced extra bristles at the approximate center of the disc. A $10-$ to 18 -hr shift produced extra bristles at the periphery (and baldness at the center; see below). Thus, the region of susceptibility to extra bristles began at the center and radiated outward. This pattern reflects the normal radial progression of bristle development (R.L. Cagan and D.F. Ready, in prep.). Although the anterior and posterior edges of the disc are bald in a normal eye, 8- to 16-hr shifts produced the same preponderance of bristles at the edges of the eye as elsewhere. Thus, the cells at these edges are capable of producing bristles, and normal Notch activity is required to suppress bristle formation in these regions.

Later shifts produced bald eyes Temperature shifts of 12- to 24-hr produced bald eyes (Figs. 4D, 6, and 7). In extreme cases, over $90 \%$ of the bristles were removed from the eye. In three 14- to 22-hr shifted retinas, only 41 bristles were found, compared to about 1800 bristles expected in unshifted eyes. When the bristle is absent, it often is replaced by an apparently normal tertiary pig- 

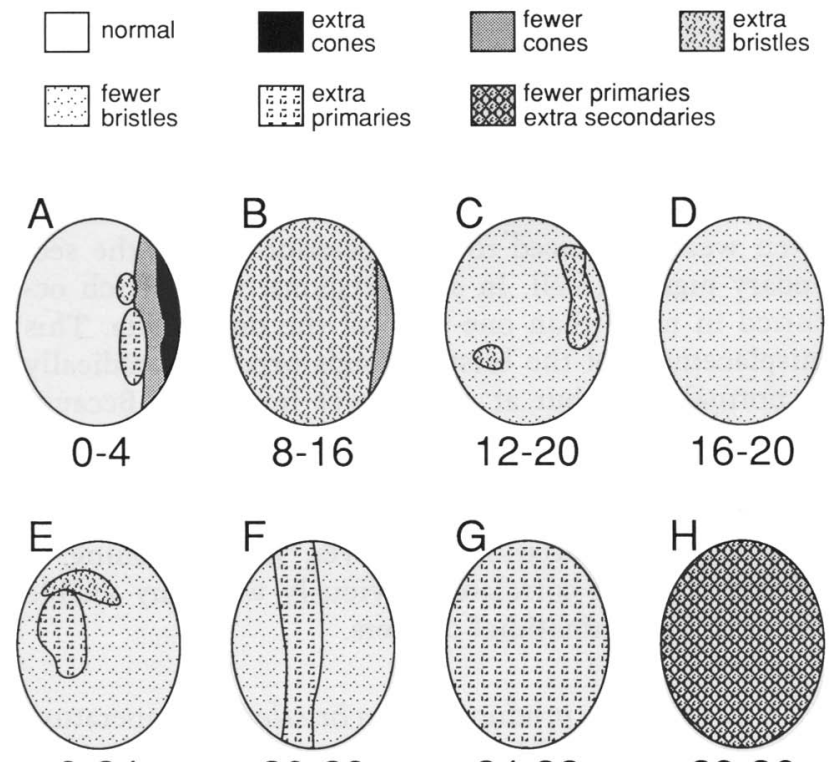

24-32

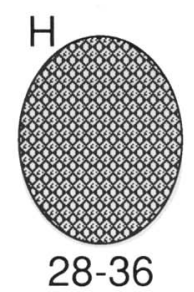

Figure 6. The distribution of defects produced with succeeding temperature shifts. Schematic of the surfaces of representative $N^{t s 1}$ eye discs shifted briefly to $32^{\circ} \mathrm{C}$ at successive stages. These discs were stained with cobalt sulfide $60 \mathrm{hr}$ after pupation and their surfaces were examined as in Fig. 5. The legend at the top defines the fill patterns as particular defects. The numbers below each disc indicate the duration of the shift in hours after pupation. (A) Similar to temperature shifts in a very mature larval disc; the morphogenetic furrow was near the anterior edge at the time of the shift. Cones and primary pigment cells were affected; underneath, photoreceptors were disturbed. $(B-F)$ Abnormal numbers of bristles. In each of these eyes, bristle defects covered the whole eye uniformly. The shift in $E$ includes both the periods for extra bristles and for baldness; the eye is bald. $(G)$ Additional primary pigment cells are produced throughout the eye. $(H)$ Phenocopy of $f a^{8}$. Anterior is to the right.

ment cell (Fig. 4D). As a result, the hexagonal lattice surrounding the ommatidia generally is undisturbed. Unfortunately, the heavy mortality of animals that were both injected with bromodeoxyuridine and temperatureshifted at this time prevented us from determining whether baldness was due to a block in mitoses or an inability of the bristle group cells to differentiate correctly.

The effects of temperature shifts that produced extra bristles were superseded by later shifts, which caused baldness. Eyes were shifted to $32^{\circ} \mathrm{C}$ between $8 \mathrm{hr}$ and 24 $\mathrm{hr}$ of pupation, covering both the periods of increased bristles and loss of bristles. These eyes were bald (Fig. $6 \mathrm{E})$. Furthermore, the temperature-sensitive periods for gain and loss of bristles overlapped: a 12- to 16-hr shift produced an eye that was bald in the center, but had excess bristles at the periphery.

\section{Reducing Notch activity affected pigment cell development}

During early pupation, bristles and pigment cells are arranged into a hexagonal lattice around the clusters (R.L.
Cagan and D.F. Ready, in prep.) Beginning about $20 \mathrm{hr}$ after pupariation, two primary pigment cells are added around each ommatidial cluster, followed closely by the sorting of the secondary and tertiary pigments cells into the interommatidial lattice. Although the pigment cells develop in a posterior-to-anterior gradient, the gradient is not sharp; reducing Notch activity during each of these pupal cell decisions required temperature-shifting successively older discs.

Shifts at two different developmental stages resulted in extra primary pigment cells Normally, each ommatidium contains two primary pigment cells. However, in larval-shifted discs examined at $60 \mathrm{hr}$ after pupariation, some ommatidia had three primary pigment cells instead of the normal two (Fig. 6A). These extra primary pigment cells were found in a region about 10 rows behind the neuralized region at the morphogenetic furrow. Other cells of the ommatidial cluster appeared normal. These three primary pigments cells were generally of equal size at the apical surface, although one cell was occasionally much smaller than the other two. Because the primary pigment cells do not differentiate for at least another $20 \mathrm{hr}$ (R.L. Cagan and D.F. Ready, in prep.), the temperature shift is unlikely to be affecting the primary pigment cells directly.

Shifts $20-28 \mathrm{hr}$ after pupariation also produced ommatidia with three primary pigment cells (Figs. 4D, 6, and 7). This correlates with the beginning of primary pigment cell development, which normally begins at about $20 \mathrm{hr}$. The three primary pigment cells occupied equal areas at the apical surface. The surrounding lattice of secondary and tertiary pigment cells was not affected by the extra primary pigment cells. Few affected ommatidia had more than three. Extra primary pigment cells were more widespread when flies were temperatureshifted during this period than when shifted as larvae; in some eyes, over a third of the retina contained ommatidia with three primary pigment cells.

Later shifts removed primary pigment cells and produced extra secondary pigment cells Reversing the phenotype seen in the previous period, temperature shifts begun after $24 \mathrm{hr}$ blocked formation of the primary pigment cells. Instead, a surplus of cells resembling secondary pigment cells surrounded the ommatidia (Fig. $4 E)$.

Primary pigment cells can be recognized by several criteria in a $60-\mathrm{hr}$ pupal retina. Most of their volume resides apically, so they appear wide at the apical surface, and their nucleus is higher than other pigment cells. Later in development, they accumulate large, brown ommachrome pigment granules. By these criteria, retinas receiving a temperature shift at this period lose more than $90 \%$ of their primary pigment cells. In approximately 4500 ommatidia examined in six $N^{t s 1}$ flies shifted $28-36 \mathrm{hr}$ after pupation, only 626 of the expected 8500 primary pigment cells are found. When flies shifted during this time period were allowed to eclose as adults, few primary pigment cells were found. The other om- 


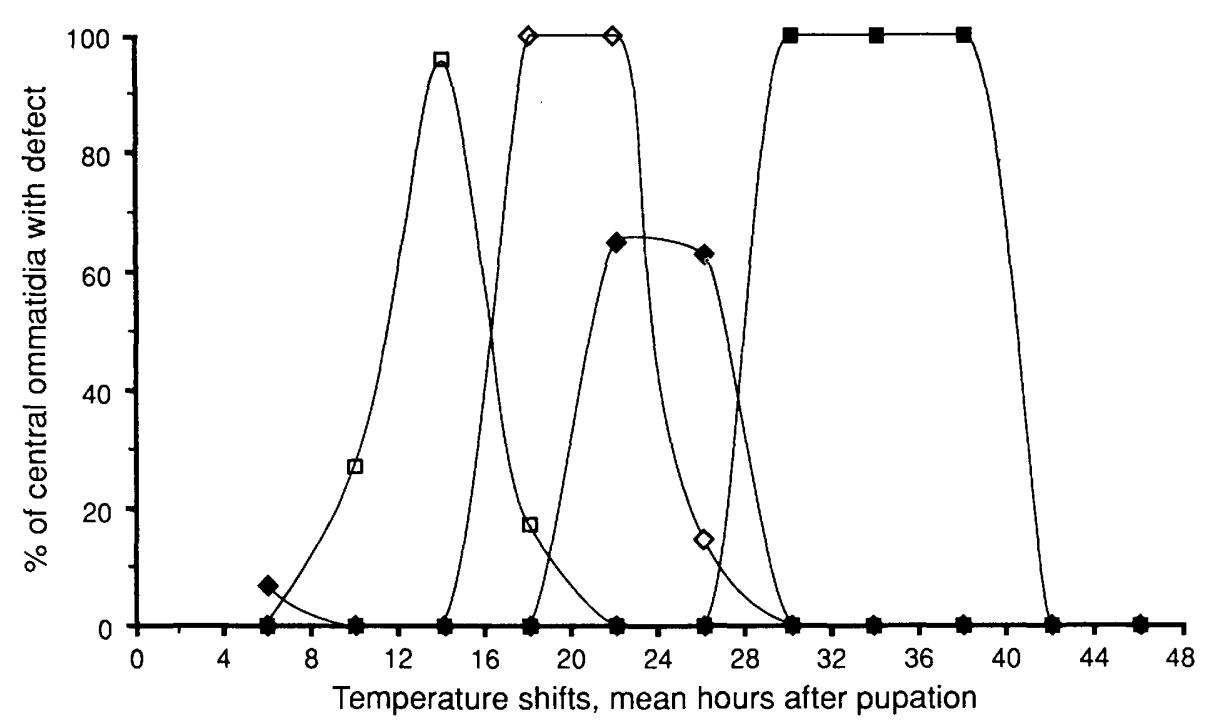

Figure 7. Quantitative measure of the defects produced with succeeding temperature shifts in the pupa. Graph shows four temperature-sensitive periods. At least 25 ommatidia from the approximate center of three eyes (at least 75 total ommatidia) were counted for each temperature shift. The $x$ axis represents midpoint of 8 -hr shifts beginning $2,6,10, \ldots 42 \mathrm{hr}$ after pupation. The $y$ axis is the percentage of ommatidia with the defect measured (not the number of defects in each ommatidium). Abbreviations: ( ${ }^{\circ}$ s $s$ ) Primary pigment cells; $\left(2^{\circ}\right.$-like $)$ cells resembling secondary pigment cells. $(\square)$ Gain bristles; $(\diamond)$ lose bristles; $(\bullet)$ gain $1^{\circ}$ s; $(\square)$ lose $1^{\circ}$ s, gain $2^{\circ}$-like cells.

machrome-containing cells-photoreceptors and cone cells - were unaffected. The elaboration of pigment, rhabdomeres, and lenses occurred on a normal schedule.

Secondary pigment cells can be distinguished also by morphology and pigmentation. Their nucleus and much of their volume is found basally, and they accumulate red pteridine pigment granules during late pupal life. By this criterion, ommatidia of $N^{t s 1}$ flies shifted during this period were surrounded by an excess of secondary-like pigment cells. The excess cells crowded the apical surface, reducing the apical profiles of the cone cells (Fig. 4E). The failure of the primary and secondary pigment cells to develop normally prevented the formation of an orderly pigment cell lattice. As a result, the lattice failed to align the ommatidia properly in these eyes. The corneal facets on the outside of adult eyes are also less well-defined than normal, giving the eye a glossy appearance. The phenotype of eyes shifted during this period resembled those of facet-glossy flies, described below.

Shifts after $40 \mathrm{hr}$ produced few defects Temperature shifts between 40 and $58 \mathrm{hr}$ had little effect. Infrequently, secondary pigment cells were lost, giving rise to five-sided ommatidia. This defect occurred in fewer than one-third of the retinas, and in not more than 10 ommatidia in a single retina.

split split is a recessive, homozygous viable allele of the Notch locus. It is characterized by small, rough eyes and twinned thoracic bristles (Welshons 1965). Temperature shifts of the third-instar $N^{t s 1}$ larvae phenocopy the external defects of split eyes (Shellenbarger and Mohler 1975).
The general layout of a split third-instar disc is fairly normal: It contains a well-defined morphogenetic furrow and a subsequent wave of mitosis, and the developing ommatidia generally are properly spaced. However, closer examination revealed defects early in ommatidial development. Normally, development begins when clusters of six to seven cells emerge from the morphogenetic furrow (Fig. 2A). In split discs, these initial clusters often are arranged poorly and contain an abnormal number of cells (Fig. 2C). Rarely, a single isolated photoreceptor is found. The second wave of mitoses generally occurs in the proper region, but, as shown in Figure 2C, mitotic figures occasionally can occur abnormally close to the furrow.

As the split eye matures, the ommatidia reflect this early defect. By midpupation ommatidia often contain fewer or, less often, more than the normal complement of eight photoreceptors (see Fig. 9A, below). In place of the normal four cone cells, ommatidia often contain two, three, or five cones. The primary pigments cells rarely are affected, but the hexagonal lattice of secondary and tertiary pigment cells is very disturbed; generally fewer secondary pigment cells surround the ommatidia and bristles are scattered. Photoreceptors can be found beneath the retina. Thus, the split eye shares many of the features of a $N^{t s 1}$ eye temperature-shifted during the third instar.

The split eye is smaller than normal. When raised at $20^{\circ} \mathrm{C}$, male split flies averaged 457 ommatidia per eye $(n=5)$ and females averaged 544 ommatidia $(n=5)$. This is significantly lower than wild-type flies, which averaged 702 and 764 ommatidia per eye for males and females, respectively $(n=5)$. Although the background 


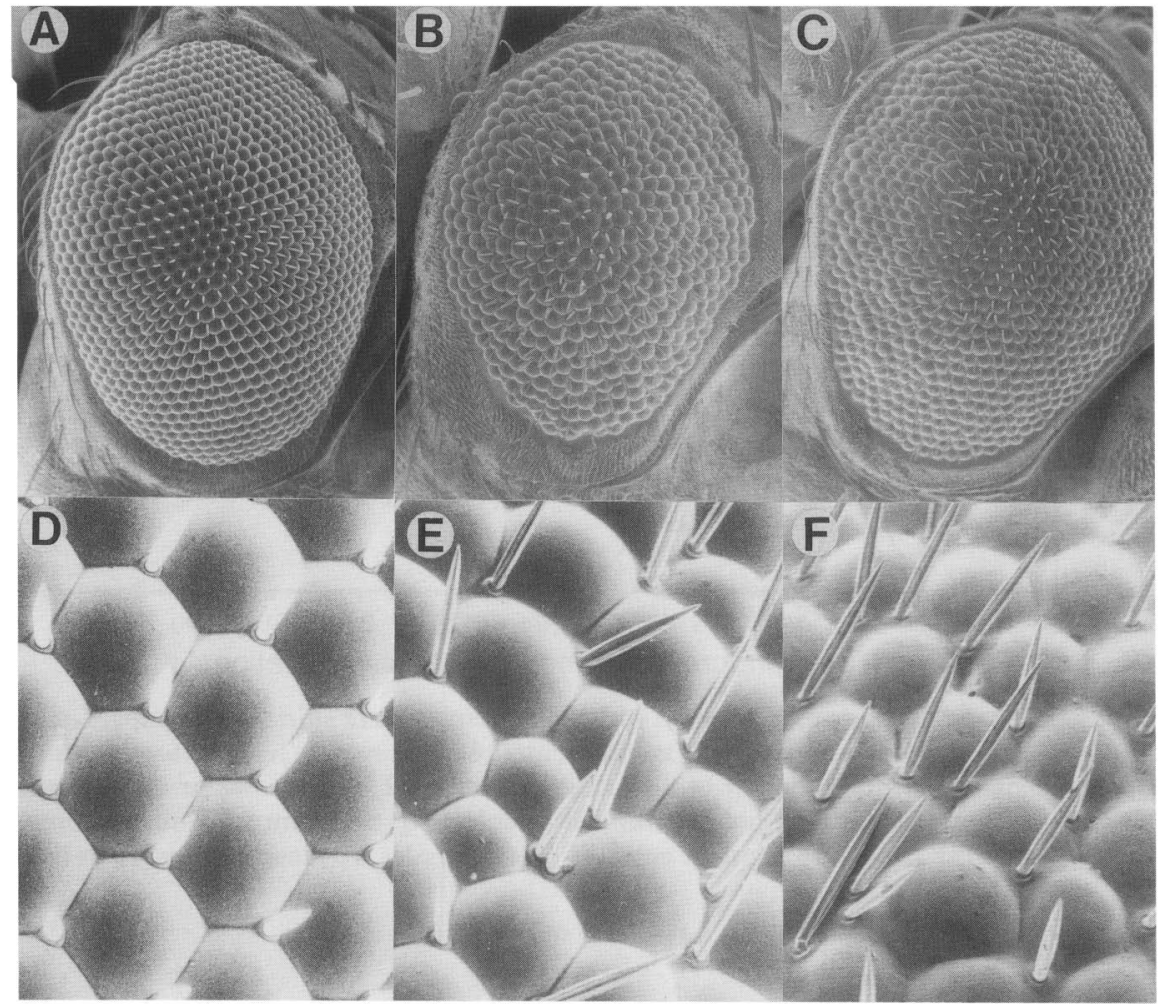

Figure 8. Comparing wild-type, split, and facet-glossy adult flies. Scanning electron micrographs of the surface. $(A, D)$ Wild type. A single ommatidium is underneath each of the several hundred corneal lenses. Lenses are aligned in straight rows, and are packed tightly together to form a sharply delineated hexagon. Bristles are evenly distributed at alternating vertices. $(B, E)$ split. The eye is smaller, the lenses are poorly aligned and of varying size, and the bristles are scattered. $(C, F)$ facet-glossy. Rows are poorly aligned and bristles are scattered. Lenses are smaller and are separated from their neighbors by broad valleys. These defects can be explained by defects in the underlying pigment cell lattice. The larger lens in the lower foreground of $E$ is likely the result of a rare underlying primary pigment cell. Bar, $50 \mu \mathrm{m}$ in $A, B, C$, and $10 \mu \mathrm{m}$, in $D, E$, and $F$; anterior is to the right.

of split flies is unknown, the difference in ommatidial number appears to be too great to be explained by strain differences.

facet-glossy The facets are a series of alleles at the Notch locus that primarily affect the eye. The corneal lenses of these mutants are separated by a shallow trough rather than the normal sharp crevice that delimits normal lenses. As a result, the eye has a smooth, glossy appearance (Fig. 8C, F). The ommatidial array is also less regular than in normal eyes. Waddington and Pilkington (1945) reported that facet has enlarged secondary pigment cells. Shellenbarger and Mohler (1975) reported that temperature shifts of $N^{t s 1}$ pupae phenocopied the external appearance of another member of this series, facet-glossy $\left(f a^{g}\right)$. To extend this analysis more fully to the cellular level and understand the origin of its defect, we studied the development of $f a^{g}$ eyes. This

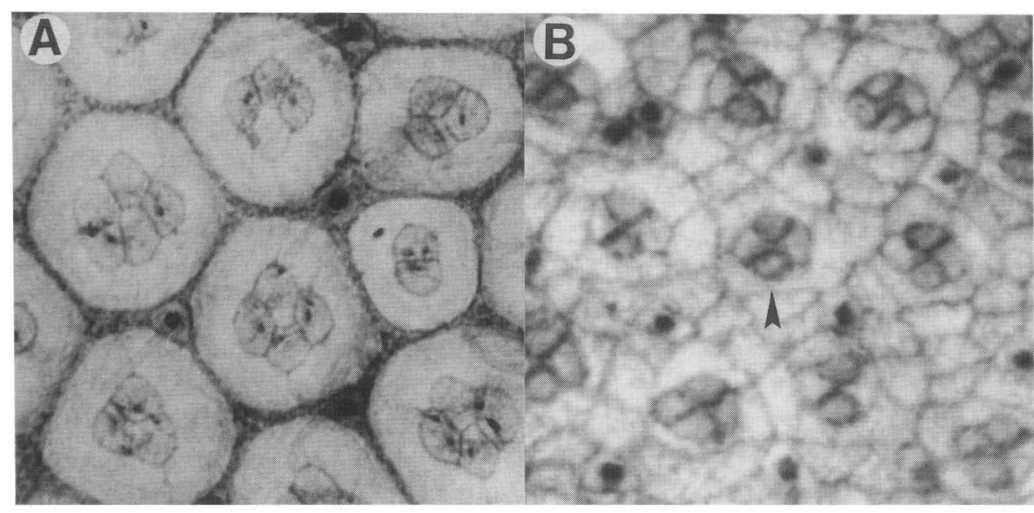

Figure 9. Cobalt sulfide-stained apical surfaces of split and facet-glossy midpupal eyes. Compare with Fig. 4A. (A) split 65 -hr eye. The two ommatidial clusters in the center have the normal complement of four cone cells, but are surrounded by clusters with two, three, and five cone cells. The hexagonal array and bristle distribution are disturbed. (B) facet-glossy 55-hr eye. The apical profiles of the cone cells are smaller due to the crowding of extra cells in the surrounding lattice; one cone cell quartet is indicated with a large arrow. Compare with Fig. 4E. Bar, $5 \mu \mathrm{m}$; anterior is to the right. 
should, in turn, provide insight into the defects produced in $N^{t s 1}$ flies, which phenocopy $f a^{g}$ when they receive selected temperature shifts.

Beneath the cornea of $f a^{g}$ flies, the eight photoreceptors and four cone cells that lie at the core of the ommatidia are normal; however, the pigment cell lattice that normally aligns these groups is in disarray. Few ommachrome-containing primary pigment cells are present, and the surround is instead dominated by an excess of pteridine-containing, secondary-like pigment cells (Fig. 10). The correct number of bristles is present, but the bristles are not properly placed.

The development of $f a^{g}$ third-instar eye discs is normal; the photoreceptor and cone cell clusters form properly. In the young pupa, bristle development is also normal; the poor placement of the bristles is due to subsequent problems in pigment cell development. The first defect is seen in formation of the primary pigment cells. In a wild-type retina, two cells surround the cone cells apically and then extend this contact basally, thus forming a collar around the four cone cells. Midway through this process, each prospective primary spreads over the back of the anterior or posterior cone cell along its entire length. Later, the developing primary pigment cells pull off the bottom and rise to lie near the surface, accumulating large brown ommachrome pigment granules (R.L. Cagan and D.F. Ready, in prep.).

In the $f a^{g}$ pupa, two cells also begin to surround the cone cells (Fig. 11A) and often meet apically. But this contact is not extended below the surface, and the two cells will separate by $60 \mathrm{hr}$ (Figs. 9B and 11B). Unlike normal primary pigment cells, these cells fail to spread fully over the cone cells or release from the bottom. In place of the normal two primary cells per ommatidia, $f a^{g}$ retinas contain less than one primary cell for every eight ommatidia. Instead, nearly all the cells surrounding the ommatidia behave like secondary pigment cells; they maintain their basal foothold, accumulate red pteridine pigment granules, and help to form the fenestrated membrane.

In addition to the loss of primary pigment cells in $f a^{g}$ flies, cell death appears to be reduced. Although ommatidia in wild type and $f a^{g}$ begin with the same number of surrounding cells at $22 \mathrm{hr}$, fewer are removed in $\mathrm{fa}^{\mathrm{g}}$ flies during subsequent development (Fig. 12). As in wildtype flies, injections of bromodeoxyuridine in $f a^{g}$ pupae labeled only the nuclei of the bristle group, suggesting that supernumerary cell divisions do not account for the extra cells. Instead, the extra cells appear to result from the loss of cell death that should occur during development of the pigment cells; this cell death normally serves to tighten the pigment cell lattice and align the ommatidia and bristles.

The loss of primary pigment cells deprives each ommatidium of two major contributors to lens formation. Normally, the cones and primary pigment cells secrete the thick biconvex corneal lens. The surrounding secondary pigment cells secrete a thin cuticle, which connects the lenses. These two cuticles can be distinguished by the intensity of their staining with $\mathrm{KMnO}_{4}$ - the secondary pigment cells secrete a more darkly staining material. In $f a^{8}$ eyes stained with $\mathrm{KMnO}_{4}$, small islands of pale-stained lenses lie above the cones; they are surrounded by large areas of thin, darkly stained cuticle secreted by the underlying secondary-like pigment cells. The result is a glossy eye.

The number of ommatidia in $f^{g}$ flies should be normal: Ommatidial number is set during the third in-

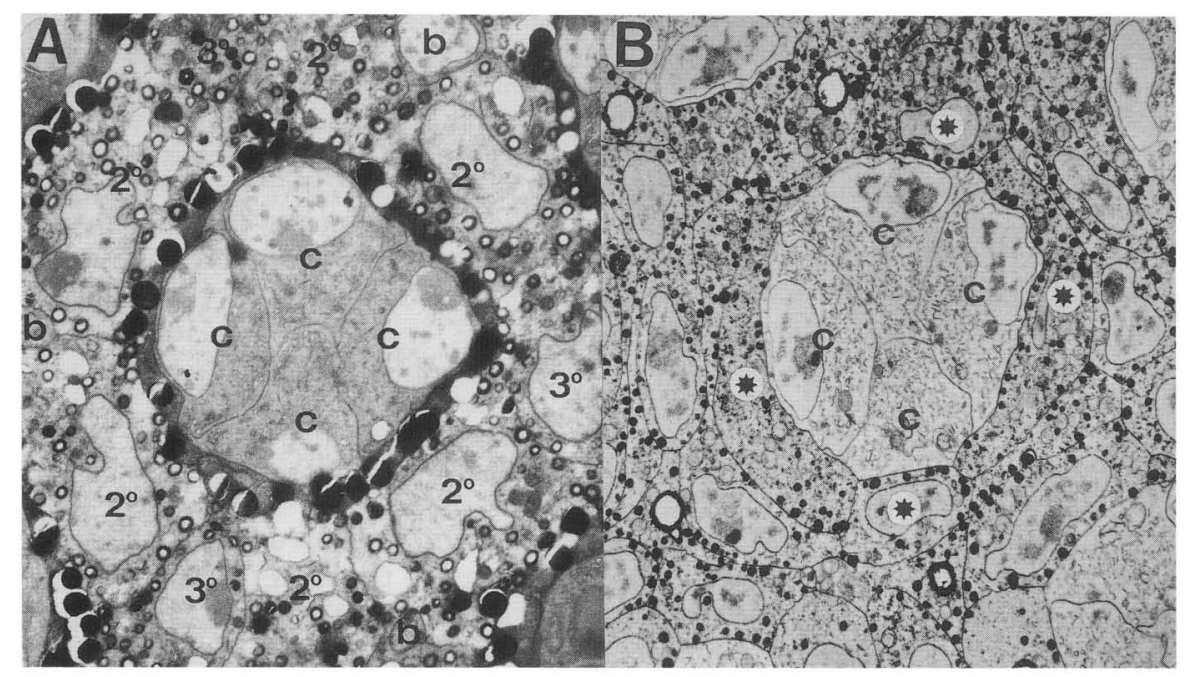

Figure 10. Comparing wild-type and facet-glossy adults. Transmission electron micrographs of single ommatidia $10 \mu \mathrm{m}$ below the surface. $(A)$ Wild type. The four central cone cells are surrounded by a dark ring, the two primary pigment cells. The primary pigment cells are filled with large ommachrome pigment granules. Around this ring are the secondary and tertiary pigments cells, which contain smaller pteridine pigment granules. $(B)$ facet-glossy. The four central cone cells are contacted by four cells $\left({ }^{*}\right)$ which contain the smaller pteridine pigment granules. Around these is a further excess of pteridine-containing cells. No primary pigment cells are present. Bar, $5 \mu \mathrm{m}$; anterior is to the right. 
Cagan and Ready

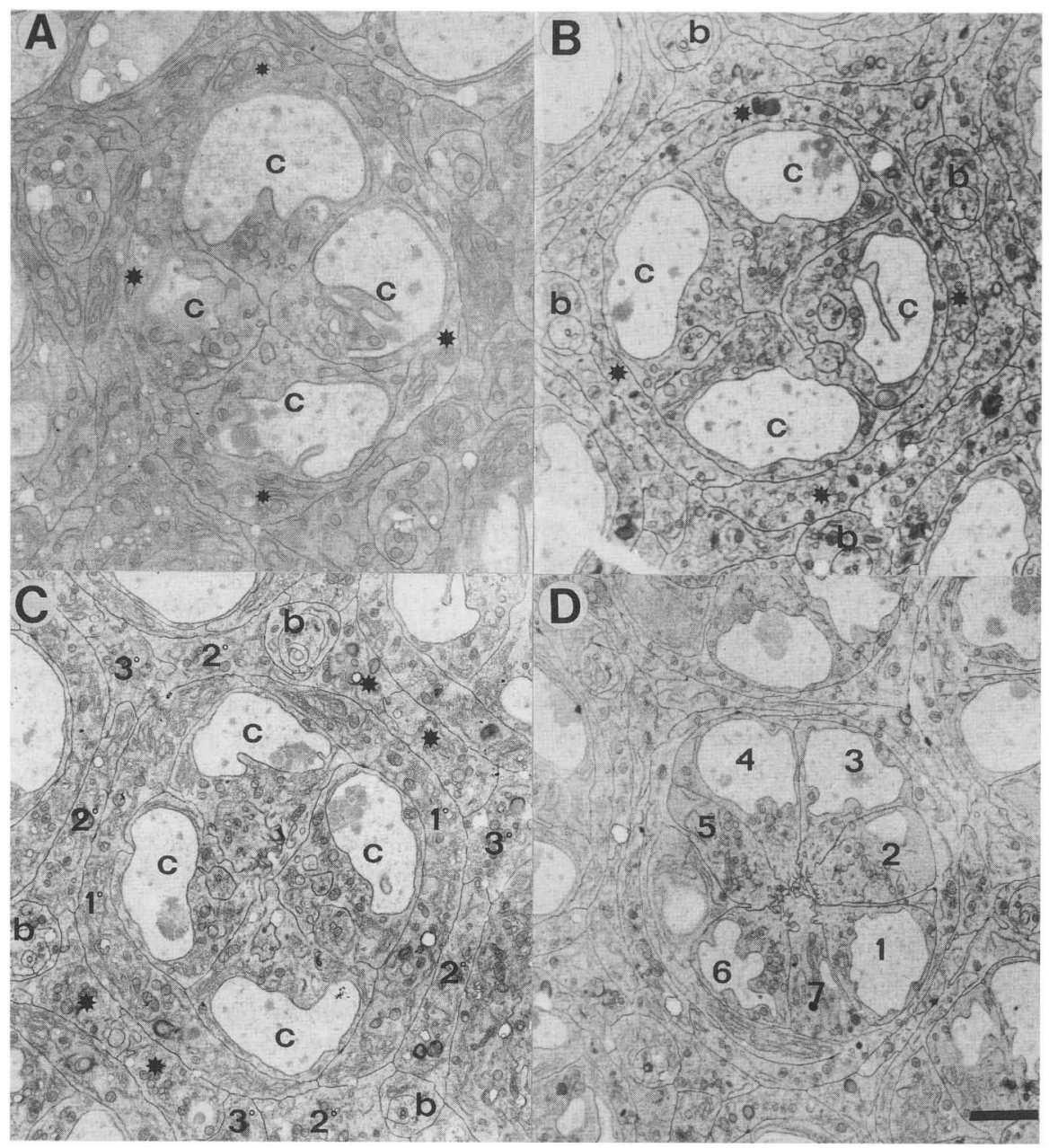

Figure 11. Pigment cell development in the facet-glossy retina. Electron micrographs showing cross sections of a single ommatidium $2 \mu \mathrm{m}(A-C)$ and $5 \mu \mathrm{m}(D)$ below the surface. (A) A 34-hr facet-glossy pupa. Two cells (large asterisks) contacting the anterior or posterior cone cells begin to encircle the cone cells, pushing intervening cells aside. At this stage, two other cells (small asterisks) continue to contact the cone cells. This stage is indistinguishable from normal development (Fig. 6B; R.L. Cagan and D.F. Ready, in prep.). (B) A 64-hr facet-glossy pupa. Unlike normal development, the two cells fail to encircle the cone cells fully, and other cells continue to contact the cone cells. This is the first observed defect in facet-glossy flies. A further excess of cells is in the space between ommatidia. All of these cells will resemble secondary pigment cells in the adult. (C) A 64-hr wild-type pupa presented for comparison to $B$. Except for a few cells to be sorted into oblique secondary pigments cells $\left({ }^{*}\right)$, the hexagonal lattice surrounding the cone cells is complete. $(D)$ A 64-hr facet-glossy pupa (a lower view). Beneath the cone cells, the photoreceptors develop normally. Photoreceptors R1-R7 (1-7) are visible at this level. The membrane ruffling at the center of the ommatidium is the beginning of rhabdomere formation, which occurs at the same stage as a wild-type retina. Again, the ommatidium is surrounded by an excess of cells. Abbreviations: $\left(1^{\circ}\right)$ Primary pigment cell; $\left(2^{\circ}\right)$ secondary pigment cells; $\left(3^{\circ}\right)$ tertiary pigment cells; (b) bristle; (c) cone cell. Bar, 3 $\mu \mathrm{m}$; anterior is to the right.

star, and $f a^{8}$ eyes appear to develop normally during this time. We counted an average of 631 ommatidia per eye in male $f a^{g}$ flies $(n=5)$, and 688 ommatidia per eye in females $(n=5)$. $f a^{g-r-1}$, a revertant of $f a^{8}$ which appears to have a normal eye (kindly supplied by Dr. S. ArtavanisTsakonis), had 649 ommatidia per eye in males $(n=5)$ and 692 ommatidia per eye in females $(n=5)$. Wild-type Canton Special flies averaged more ommatidia in each eye: 702 ommatidia in males $(n=5)$ and 764 ommatidia in females $(n=5)$. Little difference was observed between $f a^{g}$ and its revertant. Differences with wild type may reflect strain differences.

\section{Discussion}

The results presented here implicate Notch in cell fate decisions at the time the decision is made. Reducing Notch activity at specific intervals produces defects in specific cells. Early temperature shifts affected photoreceptor and cone cell development; later, bristles were affected, then pigment cells. Each cell changed its developmental program if Notch activity was reduced when that cell normally would begin its differentiation. All cell decisions in the retina, both neural and nonneural, were affected by loss of Notch activity: photoreceptors 


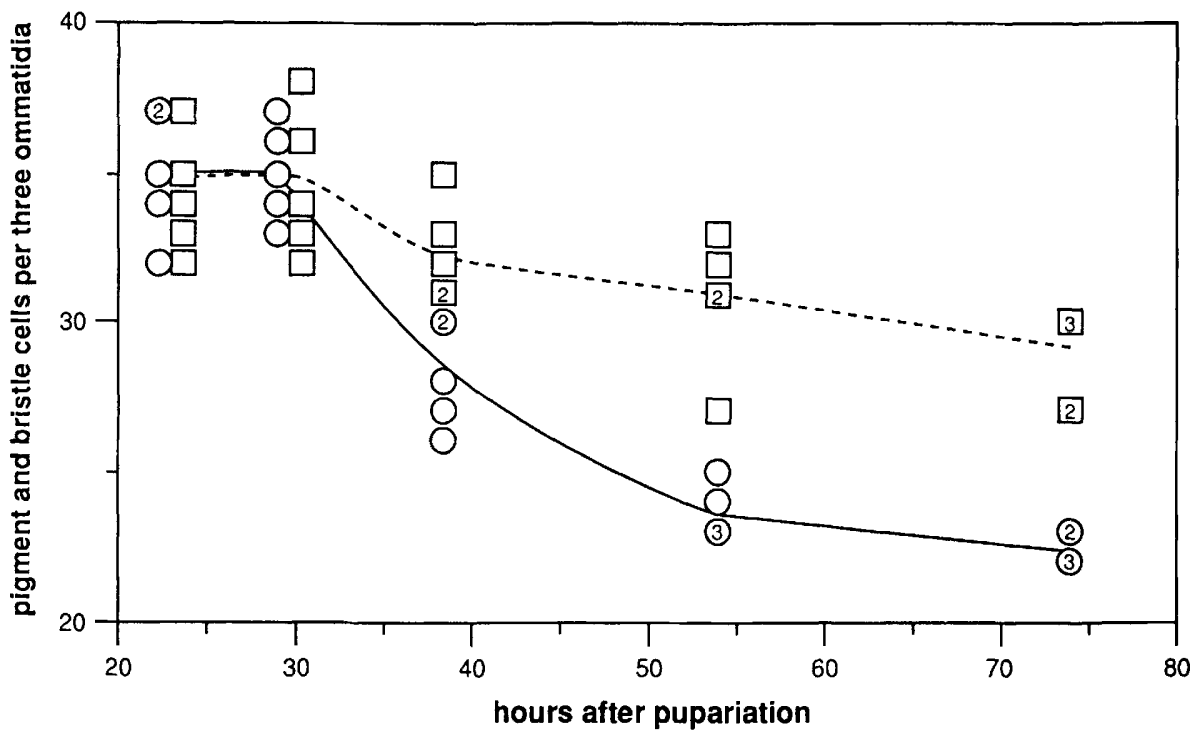

Figure 12. Cell death is affected in facet-glossy flies. Using Feulgen's stain to highlight nuclei, the number of pigment cells and bristles were counted within a defined area; this area is the equivalent of three ommatidia (see Methods). Although both begin with the same number at $22 \mathrm{hr}$, a difference is apparent between wild type (O) and facet-glossy ( $\square$ ) by $36 \mathrm{hr}$. This difference widens over the next $20 \mathrm{hr}$. Most of the programmed cell deaths that help form the pigment cell lattice occur during this interval. The lines connect the average of the five data points; numbers within a box or circle indicate multiple counts at that cell number. The four cells of the bristle group found in later counts were counted as a single cell, because they were derived from a single mother cell (R.L. Cagan and D.F. Ready, in prep.). (이 Wild type; ( $\square$ ) facet-glossy.

were affected by temperature shifts in the larva and pigment cells were affected by later pupal shifts.

Cells in the eye make use of positional information to select their fate (Ready et al. 1976; Tomlinson and Ready 1987). They appear to interpret particular combinations of cell-cell contacts to produce specific cell types. Reducing Notch activity disrupts cell decisions at the time they are made, suggesting that Notch plays a role in communication between cells. Similar models have been invoked to explain the defects seen in Notch embryos (Artavanis-Tsakonis 1988; Campos-Ortega 1988). Notch may instruct each new cell decision, or it may simply permit interactions by other, more specific mechanisms. The diverse cell decisions affected by successive temperature shifts support the second, more general role for Notch.

Notch may facilitate cell-cell communication by a general process such as adhesion. For example, in $f a^{g}$ flies, although the two prospective primary pigment cells do spread around the cone cells to contact each other at the apical surface, they fail to extend these contacts basally. Instead, these contacts are lost as the eye expands. The pattern of Notch transcripts in the embryo, which corresponds roughly to the pattern of mitoses, has prompted the suggestion that Notch may be involved in cell mitoses (Artavanis-Tsakonis 1988). Although some of the defects we see occur in a region of mitoses (i.e., formation of the photoreceptor cells and bristles), others do not. This is especially clear in the defects found in the pigment cells, which differentiate at least $24 \mathrm{hr}$ after the mitoses that formed them.

Timing is an important element in cell decisions. When Notch's activity is restored at the conclusion of a temperature shift, cells choose fates relevant to the new time, although their positions in the growing ommatidium have not changed. For example, in eyes receiving 24- to 30 -hr temperature shifts, cells positioned to become primary pigment cells instead become secondary pigment cells. A temporal window of competence to become the primary pigment cell appears to have closed. Timing also may play a role in the determination of R7 (Basler and Hafen 1989; Bowtell et al. 1989).

Temperature shifts of mature $N^{t s 1}$ larva result in most of the cells at the furrow becoming photoreceptors. A similar increase was seen when Notch clones were generated with mitotic recombination (Dietrich and Campos-Ortega 1984). This observation has strong parallels with the effects of Notch on neurogenesis in the embryo. Here a loss of Notch causes a massive neuralization in the ventral neurogenic region. Normally only a fraction of these cells become neurons and Notch is needed to selection this fraction. Studies in the grasshopper suggest that cells of the neurogenic region are equipotent, but that the decision of one cell to become a neuroblast inhibits neighboring cells from adopting this fate. Ablation studies suggest that this inhibition is communicated by direct cell contact (Doe and Goodman 1985). At the furrow, the number of founder cellsperhaps the mystery cells (Fig. 2A) - may be limited by a similar mechanism mediated by Notch. The extra mystery cells produced by early temperature shifts may in turn recruit an excess of photoreceptors, or they may themselves adopt the photoreceptor pathway.

Temperature-shifting $N^{t s 1}$ flies has allowed us to dissect cell decisions that are separated by several hours. For example, differentiation of the photoreceptors was 
separated from the cone cells, bristles, and pigments cells. Clusters assemble quickly behind the furrow, with the notable exception of $R 7$, which is added fairly late (Tomlinson 1985; Tomlinson and Ready 1987). Temperature shifts appear to be too coarse to dissect the early formation of the photoreceptor clusters, but can sometimes remove $\mathrm{R} 7$.

Formation of a bristle group begins with the appearance of a bristle mother cell, which then gives rise to the four cells that form the bristle (R.L. Cagan and D.F. Ready, in prep.). Shifts of $N^{t s 1}$ flies just before the bristle groups begin to form result in extra bristles. The pattern of labeling with bromodeoxyuridine in these eyes suggests that the temperature shifts have caused the formation of too many bristle mother cells. Bristles are even stimulated to arise at the normally bald anterior and posterior edges, again implicating Notch in the initial decision of whether cells form a bristle. The presence of one bristle mother cell appears to prevent nearby cells from also becoming bristle mother cells. Previous models for bristle spacing also have postulated a suppression of additional bristle formation surrounding a bristle mother cell, usually by a diffusible inhibitor (Wigglesworth 1941; Stern 1954; Moscoso del Prado and Garcia-Bellido 1984). However, the restricted space between ommatidia in which the retinal bristles arise may allow inhibition by a more local, contact-based mechanism. Loss of Notch activity may block this inhibition.

Shifts in two different temperature-sensitive periods can result in the addition of an extra primary pigment cell to $N^{t s 1}$ ommatidia. The first period in the mature larva precedes by at least a day the time of primary pigment cell differentiation. The second occurs in the early pupa, as prospective primary pigment cells first arise. The addition of an extra primary pigment cell during larval shifts appears to be due to a secondary effect of defects in other earlier developing cells. Extra primary pigment cells arise near the region of cone cell defects. Perhaps the cone cells, which appear normal, are defective in their ability to limit later the number of primary pigment cells. This delayed effect is further evidence that cells can direct the fate of their neighbors. Analogous situations are found in bride-of-sevenless, where mosaic studies suggest that boss is required for photoreceptor R8 to direct the later differentiation of R7 (Reinke and Zipursky 1988), and rough, which is required in R2 and $\mathrm{R} 5$ for the subsequent differentiation of $\mathrm{R} 3$ and $\mathrm{R} 4$ (Tomlinson et al. 1988).

The rough eyes of $f a^{g}$ and its $N^{t s 1}$ phenocopy are due in part to a decrease in the programmed cell death that normally tightens and refines the pigment cell lattice. The blocking of cell death when Notch activity is reduced suggests that cell death is not the default pathway (the fate achieved when no communication is made). Instead, a cell must be directed by its neighbors to die. Loss of cell communication throughout early pupation instead results in the production of extra secondary pigment cells. This appears to be the default fate. Temperature shifts did not separate the loss of primary pigment cells, gain of secondary pigment cells, and decrease in programmed cell death, suggesting these cell choices may be linked. This is consistent with their developmental histories in normal development (R.L. Cagan and D.F. Ready, in prep.).

The defects seen in $f a^{g}$ and pupal-shifted $N^{t s 1}$ eyes both are a consequence of the failure of primary pigment cells to differentiate normally. But the defects seen in $f a^{g}$ appear to be more specific than simply a sudden, timespecific loss of Notch function. $f a^{g}$ affects only pigment cells, and affects them equally throughout the eye. Temperature shifts during the transition from baldness to pigment cell defects produced patches containing one or both defects. Much later shifts removed only a few primaries. $f a^{g}$ was only completely phenocopied by temperature shifts done within a narrow window of time $(28-36 \mathrm{hr})$. It is possible that Notch activity is first lost throughout $f a^{g}$ flies within this interval. More likely, loss is due to processes specific to pigment cells. The defects in $f a^{g}$ are due to a copia-like element inserted into Notch's second intron (Kidd and Young 1986). Perhaps the molecular mechanisms invoked to produce pigment cells affect the insertion element, causing inactivation of Notch. Or perhaps disruption of the second intron affects sites that specifically regulate Notch function in pigment cells.

The phenotype of split and the defects produced by larval temperature shifts of $N^{t s}$ both have their origin in the abnormal differentiation of photoreceptors at the furrow. However, in split, the loss of Notch function again appears to be more specific. A loss of Notch function in temperature-shifted eyes produced extensive neuralization, whereas in split the groups of cells that break from the furrow cannot assemble correctly and often have fewer cells. Most likely, this difference reflects a greater number of cell decisions or greater sensitivity that recruitment of cells into clusters may entail when compared with the initial decision of ommatidial spacing. The defects of split flies are the result of a single amino acid change in the extracellular epidermal growth factor-like region; this change may affect interactions by Notch with itself or with other proteins (Hartley et al. 1987; Kelley et al. 1987). The severe, tissue-specific defects of split suggest that this site is of special importance to cell decisions in the eye.

In conclusion, our work suggests that Notch is required in decisions of every cell type in the eye. This is consistent with the idea that Notch is required for local cell contacts. Removal of Notch activity appears to make cells blind to their surroundings; restoring Notch activity then allows a correctly positioned cell to choose a cell fate appropriate to the current maturity of its environment. If Notch activity is not restored, cells eventually adopt a default state as a photoreceptor or secondary pigment cell. Thus, the retina makes use of timing as well as positional information to guide cells to their proper fate, and it requires Notch to do so.

\section{Methods \\ Temperature shifts}

Wild-type (Canton Special) and $N^{t s 1}$ flies were used. Temperature shifts of pupae were done by collecting white prepupae and 
maintaining at $20^{\circ} \mathrm{C}$. At 2 -hr intervals $\{0,2,4, \ldots 52 \mathrm{hr}\}$, pupae were placed in a water bath at $32^{\circ} \mathrm{C}$ for 4,8 , or $12 \mathrm{hr}$, and then returned to $20^{\circ} \mathrm{C}$. Pupae were allowed to develop until $60 \mathrm{hr}$ of age; their retinas were removed and stained with cobalt chloride. Larvae were shifted for $0,4,8, \ldots 24 \mathrm{hr}$, and then either stained with anti-HRP or processed for electron microscopy.

\section{Electron microscopy}

Dissected eyes were fixed as in R.L. Cagan and D.F. Ready (in prep.). Briefly, tissue was placed at $2 \%$ glutaraldehyde/PBS for $60 \mathrm{~min}$, then $2 \% \mathrm{KMnO}_{4} / \mathrm{PBS}$ for $45 \mathrm{~min}$. The tissue then was dehydrated and imbedded in Araldite resin. After the resin was cured, $0.1-\mu \mathrm{m}$ sections were collected serially onto Formvarcoated slot grids and viewed in a JOEL-100C-X transmission electron microscope.

\section{Light microscopy}

Tissue was fixed and embedded as described above, omitting the $\mathrm{KMnO}_{4}$. Continuous ribbons of 1 - to $4-\mu \mathrm{m}$ sections were collected onto glass coverslips, stained for $4 \mathrm{sec}$ with $1 \%$ methylene blue/azur II in $\mathrm{H}_{2} \mathrm{O}$, and mounted with DPX mounting medium. A video camera and monitor were used to enlarge the image 10-fold.

Cobalt chloride staining (Melamed and Trujillo-Cenoz 1975) is useful for visualizing the top and bottom surfaces of the disc. It also selectively stains clustering cells in the third-instar eye disc. Eyes were dissected in Ringer's, then transferred to a drop of $2 \%$ glutaraldehyde in PBS for $5 \mathrm{~min}$. The tissue was washed in distilled water for $30 \mathrm{sec}$, and then placed in $2 \% \mathrm{Co}\left(\mathrm{NO}_{3}\right)_{2}$ for $5 \mathrm{~min}$. The tissue was swirled in distilled water for $5 \mathrm{sec}$, and then stained in a drop of $1 \%\left(\mathrm{NH}_{4}\right)_{2} \mathrm{~S}$ for $10 \mathrm{sec}$. After rinsing in distilled water, the tissue was mounted on a coverslip with Aquamount.

\section{Staining larval discs with anti-horseradish peroxidase}

The procedure is similar to that of Tomlinson and Ready (1987). Eye-antennal discs were dissected from the larva and fixed for 5 min in PLP fix (ibid.) for 30 min. During fixation, the peripodial membrane was removed. Discs were washed and reacted with anti-horseradish peroxidase goat anti-mouse in $0.01 \%$ saponin/PBS for $60 \mathrm{~min}$. Discs were washed, mounted in Aquamount, and viewed as whole mounts.

\section{Cell division}

To follow cell division, pupae were injected with $5 \mathrm{mg} / \mathrm{ml}$ of bromodeoxyuridine (Becton-Dickinson) at the appropriate time, and allowed to mature until $60 \mathrm{hr}$ after pupation $\left(20^{\circ} \mathrm{C}\right)$. Dissected eyes were fixed in $70 \% \mathrm{EtOH}$ for $30 \mathrm{~min}$. An equal volume of $4 \mathrm{~N} \mathrm{HCl}$ was added and fixation was continued for an additional $30 \mathrm{~min}$ with rotation. The tissue was washed with $0.3 \%$ Triton in PBS and reacted with anti-bromodeoxyuridine mouse IgG (Becton-Dickinson) for $12 \mathrm{hr}$; the anti-mouse Vectastain $\mathrm{ABC}$ kit was used as the secondary antibody. The tissue was processed with diaminobenzidine, mounted in Aquamount, and viewed as a whole mount.

\section{Counting cells and ommatidia}

Cell numbers were counted by visualizing their nuclei with Feulgen's stain (Chayen et al. 1969). Using a video camera, images were enlarged onto a monitor. Nuclear profiles were drawn within a hexagon that connected the midpoints of six ommatidia surrounding a central seventh. Five areas at the approximate center of at least three eye discs were analyzed.

The number of ommatidia was compared in wild type, split, $f a^{g}$ and $f a^{g-r-1}$ flies by counting ommatidia in scanning electron micrographs taken at $200 \times$ magnification. Flies were used from fresh bottles grown in parallel at $20^{\circ} \mathrm{C}$, and one eye was counted from each fly.

\section{Acknowledgments}

We thank Dr. Spyros Artavais-Tsakonis for providing $f a^{g}$ and $f a^{g-r-1}$ stocks. We thank Drs. Eric Wieschaus, Trudy Schupbach, Iva Greenwald, and John Yochem for helpful comments on preparing the manuscript. R.C. extends special thanks to Dr. Eric Wieschaus for his guidance and support. This work was supported by National Institutes of Health grant number $5 \mathrm{~T} 32$ GM-07312 and National Science Foundation grant numbers BNS-8318235 and BNS-8616928 A03.

\section{References}

Artavanis-Tsakonis, S. 1988. The molecular biology of the Notch locus and the fine tuning of differentiation in Drosophila. Trends Neurosci. 4(4): 95-100.

Basler, K. and E. Hafen. 1989. Ubiquitous expression of sevenless: Position-dependent specification of cell fate. Science 243: $931-934$.

Bowtell, D., M. Simon, and C. Rubin. 1989. Ommatidia in the developing Drosophila eye require and can respond to sevenless for only a restricted period. Cell 56: 931-936.

Cagan, R.L. and D.F. Ready. 1989. The emergence of order in the Drosophila pupal retina. Dev. Biol. (in press).

Campos-Ortega, J.A. 1980. On compound eye development in Drosophila melanogaster. Curr. Top. Dev. Biol. 15:347371.

1988. Cellular interactions during early neurogenesis of Drosophila melanogaster. Trends Neurosci. 9: 400-405.

Chayen, J., L. Bitensky, R. Butcher, and L. Poulter. 1969. The analysis of chemical components of cells and tissues. In $A$ guide to practical histochemistry pp. 57-61, Philadelphia.

Dietrich, U. and J.A. Campos-Ortega. 1984. The expression of neurogenic loci in imaginal epidermal cells of Drosophila melanogaster. I. Neurogenet. 1: 315-332.

Doe, C. and C. Goodman. 1985. Early events in insect neurogenesis. II. The role of cell interactions and cell lineage in the determination of neuronal precursor cells. Dev. Biol. 3: 206-219.

Foster, G.G. and D.T. Suzuki. 1970. Temperature-sensitive mutations in Drosophila melanogaster. IV. A mutation affecting eye facet arrangement in a polarized manner. Proc. Natl. Acad. Sci. 67(2): 738-745.

Greenwald, I.S. 1985. lin-12, a nematode homeotic gene, is homologous to a set of mammalian proteins that includes epidermal growth factor. Cell 43: 583-590.

Greenwald, I.S., P.W. Sternberg, and H.R. Horvitz. 1983. The lin-12 locus specifies cell fates in Caenorhabditis elegans. Cell 34: 435-444.

Hartley, D., T. Xu, and S. Artavanis-Tsakonis. 1987. The embryonic expression of the Notch locus of Drosophila melanogaster and the implications of point mutations in the extracellular EGF-like domain of the predicted protein. EMBO J. 11: 3407-3417.

Kelley, M., S. Kidd, W. Deutsch, and M. Young. 1987. Mutations altering the structure of epidermal growth factor-like coding sequences at the Drosophila Notch locus. Cell 51: $539-548$. 
Kidd, S. and M. Young. 1986. Transposon-dependent mutant phenotypes at the Notch locus of Drosophila. Nature 323: $89-91$.

Kidd, S., M. Kelly, and M. Young. 1986. Sequence of the Notch locus of Drosophila melanogaster: Relationship of the encoded protein to mammalian clotting and growth factors. Mol. Cell. Biol. 6: 3094-3108.

Kimble, J. 1981. Alterations in cell lineage following laser ablation of cells in the somatic gonad of Caenorhabditis elegans. Dev. Biol. 70: 396-417.

Lehmann, R., F. Jimenez, U. Dietrich, and J.A. Campos-Ortega. 1983. On the phenotype and development of mutants of early neurogenesis in Drosophila melanogaster. Wilhelm Roux's Arch. Dev. Biol. 192: 62-74.

Melamed, J. and O. Truillo-Cenoz. 1975. The fine structure of the eye imaginal disc in muscoid flies. I. Ultrastruc. Res. 51: 79-93.

Moscoso del Prado, J. and A. Garcia-Bellido. 1984. Cell interactions in the generation of chaetae pattern in Drosophila. Wilhelm Roux's Arch. Dev. Biol. 193: 246-251.

Poulson, D. 1937. Chromosomal deficiencies and embryonic development of Drosophila melanogaster. Proc. Natl. Acad. Sci. 23: 133-137.

Ready, D.F. 1989. A multifaceted approach to neural development. Trends Neurosci. 12: 102-109.

Ready, D.F., T.E. Hanson, and S. Benzer. 1976. Development of the Drosophila retina, a neurocrystalline lattice. Dev. Biol. 53: $217-240$.

Reinke, R. and S.L. Zipursky. 1988. Cell-cell interaction in the Drosophila retina: The bride of sevenless gene is required in photoreceptor cell R8 for R7 cell development. Cell 55: $321-330$.

Shellenbarger, D.L. and J.D. Mohler. 1975. Temperature-sensitive mutations of the Notch locus in Drosophila melanogaster. Genetics 81: 143-162.

-1978. Temperature-sensitive periods and autonomy of pleiotropic effects of $l(1) N^{t s 1}$, a conditional Notch lethal in Drosophila. Dev. Biol. 62: 423-446.

Stern, C. 1954. Two or three bristles. Am. Sci. 42: 213-247.

Tomlinson, A. 1985. The cellular dynamics of pattern formation in the eye of Drosophila. I. Embryol. Exp. Morphol. 89: $313-331$.

Tomlinson, A. and D.F. Ready. 1987. Neuronal differentiation in the Drosophila ommatidium. Dev. Biol. 120: 336-376.

Tomlinson, A., B. Kimmel, and G. Rubin. 1988. rough, a Drosophila homeobox gene required in photoreceptors R2 and R5 for inductive interactions in the developing eye. Cell 55: $771-784$.

Waddington, C.H. and R.W. Pilkington. 1944. The structure and development of four mutant eyes in Drosophila. 1 . Genet. 45: 44-50.

Welshons, W.J. 1965. Analysis of a gene in Drosophila. Science 150: $1122-1129$.

Wharton, K., K. Johansen, T. Xu, and S. Artavanis-Tsakonas. 1985. Nucleotide sequence from the neurogenic locus Notch implies a gene product that shares homology with proteins containing EGF-like repeats. Cell 43: 567-581.

Wigglesworth, V.B. 1940. Local and general factors in the development of 'pattern' in Rhodnius prolixus. J. Exp. Biol. 17: $180-200$.

Yochem, J., K. Weston, and I. Greenwald. 1988. The Caenorhabditis elegans lin-12 gene encodes a transmembrane protein with overall similarity to Drosophila Notch. Nature 335: $547-550$. 


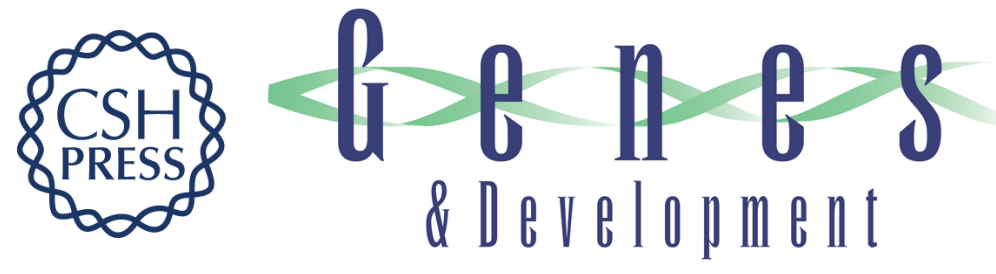

\section{Notch is required for successive cell decisions in the developing Drosophila retina.}

R L Cagan and D F Ready

Genes Dev. 1989, 3:

Access the most recent version at doi:10.1101/gad.3.8.1099

References This article cites 33 articles, 7 of which can be accessed free at:

http://genesdev.cshlp.org/content/3/8/1099.full.html\#ref-list-1

License

Email Alerting

Service

Receive free email alerts when new articles cite this article - sign up in the box at the top right corner of the article or click here.

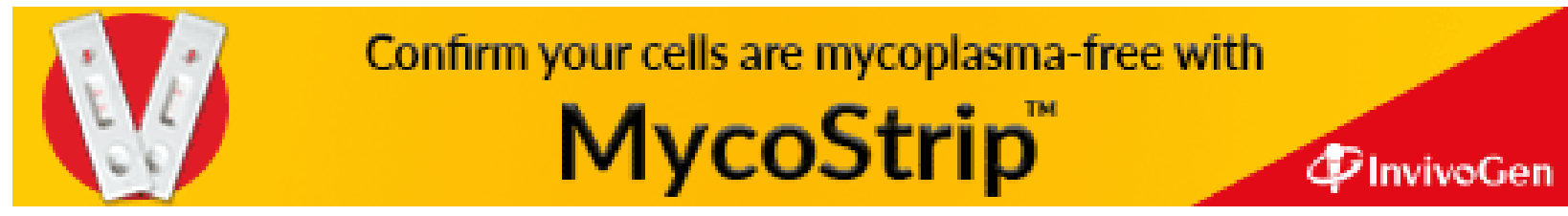

